\title{
Relation between Social Conservatism, Moral Competence, Moral Orientations, and the Importance of Moral Foundations

\author{
Ingrida Trups-Kalne
}

Riga Higher Institute of Religious Sciences affiliated to the Lateran Pontifical University

Girts Dimdins

Department of Psychology, University of Latvia

Doi: $10.1515 / m j s s-2017-0044$

\begin{abstract}
This paper examines the relation between moral competence, moral orientations, importance of moral foundations, and political orientation, by combining two theoretical approaches in moral psychology--the cognitive perspective and social-intuitionist perspective. The participants (Study $1 \mathrm{~N}=348$, aged 18 to 67, and Study $2 N=361$, aged 16 to 74) completed the Moral Competence Test (formerly Moral Judgment Test, Lind, 1978, 2008), the 30-Item Full Version of the Moral Foundations Questionnaire (Graham, Haidt \& Nosek, 2008), and measurements of political orientation (a seven-point self-evaluation scale in study 1 and an 8-item social conservatism scale in Study 2). There was a negative correlation between moral competence on the one hand and conservative political orientation and binding moral foundations on the other hand. The overall correlation pattern between the scores of moral orientation and moral competence, and importance of moral foundations and political orientation was relatively weak and only partially consistent with the theoretical predictions. The results suggest that constructs used in the cognitive and social-intuitionist perspectives on moral judgment are conceptually different, and integrating the two approaches may be a challenging task.
\end{abstract}

Keywords: Moral competence, moral foundations, conservatism, ideology, political orientation

\section{Introduction}

Based on the theoretical assumptions and empirical findings of Piaget (1932/1965) and Kohlberg (1968), Georg Lind's (2002) Dual-Aspect Theory of Moral Development postulates that moral reasoning is formed by two aspects that are inseparable in real life but are theoretically independent: the affective aspect, containing moral orientations (formed by motivation and values, which corresponds to Kohlberg's six-stage model of moral development (Kohlberg, 1976), see the Appendix of this paper for a brief summary), and the cognitive aspect (moral reasoning structure that is characterized by consistency of moral reasoning). The former aspect reflects the change in the contents of individual motivation of moral behavior, as moral reasoning changes from the selfcentered perspective of pre-conventional level of moral development to the universality of the postconventional level. This aspect contains ethical principles and individual beliefs about what is good and what is bad, and for what reason. The latter aspect reflects the individual capacity to make moral decisions and to act in accordance with them. It reflects individual skills to apply the moral knowledge to solving specific moral dilemmas. The latter aspect is also referred to as moral competence. Both aspects of morality are closely related and, in fact, the principle of cognitive- 
affective parallelism (Kohlberg, 1977, as mentioned in Lind, 2002) stipulates that the support of arguments of the highest moral development stages is related to consistency in the moral reasoning process and a hierarchy of clearer moral values and principles.

Empirical studies (Lind, 1986, 2003b) show that, irrespective of age and cultural belonging, individuals give priority to arguments of the higher moral development stages, even though not everyone has highly developed moral competence. But Lind (2002, 2003a) argues that an individual needs a highly developed moral competence in order to implement his/her declared ideals and solve moral dilemmas and conflicts in everyday life. The bigger the number of moral values and virtues an individual considers important, the higher moral competence is necessary for $\mathrm{him} /$ her to make a decision in a moral dilemma situation.

Cross-cultural research in the field of moral reasoning development (see Snarey, 1985, for a review) indicates that the level of moral development in Eastern and traditional cultures is in general lower than that in the developed Western cultures. In addition, within one culture, systematic differences in moral reasoning can be observed between various social groups. For example, a number of studies (see Emler, 2002, for a review) have revealed that individuals with conservative political orientation show lower scores on moral reasoning tests. Emler (2002) also notes that conventional reasoning is often related to social conservatism, whereas post-conventional reasoning is more closely correlated with liberalism. Social conservatism is defined here as endorsement of traditional values and exhibiting attitudes and behavior aimed at maintaining the existing organization of society, as opposed to supporting social change aimed at improvement the rights and freedoms of all individuals (the latter stance can be labeled socially liberal).

These findings regarding the differences in moral reasoning between liberals and conservatives bring up the question of how moral reasoning is measured when such comparisons are made, and how different social groups understand the concept of morality. The cognitiverational approach to moral reasoning is characterized by Turiel's (1983, p. 3) definition: "the moral domain refers to prescriptive judgments of justice, rights, and welfare pertaining to how people ought to relate to each other". It follows from this definition that any values that are not related to "justice, rights, and welfare" (such as, for example, patriotism, authority, or sanctity) are considered non-moral and relegated to the domains of social convention or personal choice (Turiel, Hildebrandt, \& Wainryb, 1991).

However, in many social groups and cultures the concept of morality is construed more broadly than outlined by the cognitive-rational approach. An alternative perspective to understanding morality, which accommodates other criteria for defining the moral domain, is the social intuitionist approach that has grown more and more prominent in social psychology over the last couple of decades (Haidt, 2001, 2007). Haidt and colleagues (Haidt, 2007; Haidt \& Joseph, 2004) have concluded that there are five psychological systems, each with its own evolutionary history, that give rise to moral intuition across cultures. The first foundation (labeled Fairness/cheating) is concerned with fairness, reciprocity and justice. The second foundation (Care/harm) is concerned with caring, nurturing, and protecting vulnerable individuals from harm. The third foundation (Loyalty/betrayal) is concerned with loyalty, patriotism, and self- sacrifice for the group, combined with vigilance for traitors. The fourth foundation (Authority/subversion) is concerned with virtues of subordinates (e.g., obedience and respect for authority) paired with virtues of authorities (such as leadership and protection), and respect for tradition. The fifth moral foundation (Sanctity/degradation) deals with avoidance of physical and spiritual contamination, and it promotes living in an elevated, less carnal, more noble way. Cultures may vary in the degree to which they construct, value, and teach virtues based on the five intuitive foundations. A number of empirical studies (Graham, Haidt, \& Nosek, 2009; Graham, Haidt, Nosek, lyer, Koleva, \& Ditto, 2011) have shown that these five foundations can be further reduced to two basic factors. The first factor, formed by the care and fairness foundations, can be considered the factor of individualizing morality (aimed at regulating interactions between individuals, and at maximizing individual welfare in such interactions). The second factor, formed by the loyalty, authority, and sanctity moral foundations, can be considered the factor of binding morality (aimed at regulating relationships within social groups, and at maximizing social harmony and welfare at the group level).

Cross-cultural studies by Haidt and colleagues (Graham, Haidt, \& Nosek, 2009; Graham, et 
al., 2011; Haidt \& Graham, 2007), using samples of tens of thousands of participants from different countries, have revealed that fairness/cheating and care/harm are more important aspects in making moral judgment for liberally oriented individuals than for conservatives, for whom in-group loyalty, respect for authority, and concern about purity and sanctity are also important. Strongly liberal individuals evaluate the first two foundations (care/harm and fairness/cheating) as highly important in their moral judgments, whereas the other three foundations are evaluated as relatively unimportant. At the same time, highly conservative respondents state that all five moral foundations are about equally important for them. These findings are part of a rapidly developing tradition in contemporary social and political psychology, which examines individual political orientation as a psychological construct and studies its psychological and behavioral correlates, antecedents, and consequences (see for example Duckitt \& Sibley, 2009; Feldman \& Johnston, 2014; Jost, Federico, \& Napier, 2009; Jost, Glaser, Kruglanski, \& Sulloway, 2003). A large part of this line of research has been devoted to the relationship between moral judgment and moral reasoning on the one hand, and political orientation on the other, mostly within the social-intuitive approach (e.g., Federico, Weber, Ergun, Hunt, 2013; Graham, et al., 2011; Kugler, Jost, \& Noorbaloochi, 2014; Nilsson \& Erlandsson, 2015; Weber \& Federico, 2013), but also within the rational-cognitive approach (e.g., Crowson \& DeBacker, 2008; Emler, 2002; Raaijmakers \& Van Hoof, 2006).

As mentioned before, previous research has shown that individuals with conservative political orientation show lower scores on moral reasoning tests (Emler, 2002). One possible explanation for these results is that the existing moral reasoning tests are largely based on moral dilemmas related to the individualizing moral foundations, which form the basis of liberal morality. According to Lind (2002), the moral competence score reflects the consistency of reasoning in relation to the values that are of importance for an individual. One may argue that it is easier to preserve this consistency of reasoning for individuals with a lesser number of morally important values (and thus achieve higher moral reasoning scores) than for individuals with a larger number of important moral values, such as conservative individuals. For conservative respondents, when solving the dilemmas, there are additional criteria to consider, related to the binding moral foundations of in-group loyalty, respect for authority, and concern over purity and sanctity, which are not reflected in the measurements and test results. Liberal respondents, for whom the individualizing moral foundations are of stronger importance, show higher scores in measurements of moral reasoning. Thus, an assumption can be made that the importance of binding moral foundations is negatively related to moral competence scores. In addition, Emler, Renvick, and Malone (1983) showed that conservative political orientation was related to support for conventional stages of moral development, whereas liberal political orientation was related to support for post-conventional moral stages.

To our knowledge, until now no direct studies of the relation between the psychological constructs of the rationalist approach and intuitionist approach to moral judgment have been carried out. Researchers of the rationalist approach and intuitionist approach have been working mainly within their respective theoretical perspectives, rarely referring to the theoretical grounds or empirical findings of the other approach (except for exchange of theoretical arguments, see, for example, Haidt, 2010; Narvaez, 2010). This study offers an attempt to investigate the overlap between the rationalist and intuitionist approaches of moral psychology. It looks at the relationship between the measures of moral competence and moral orientation on the one hand, and the importance of moral foundations on the other hand. In addition, it examines the relationship between these measures of moral judgment and individual political orientation (social conservatism).

Research hypotheses:

1. Moral competence is positively related to the importance of individualizing moral foundations (care/harm, fairness/cheating) and negatively related to the importance of binding moral foundations (loyalty/betrayal, authority/subversion, and sanctity/degradation).

2. There is a positive relationship between post-conventional (Stages 5 and 6) moral orientation and the importance of individualizing moral foundations (care/harm, fairness/reciprocity), and between conventional moral orientation (Stages 3 and 4 ) and the 
importance of binding moral foundations (loyalty/betrayal, authority/subversion, and sanctity/degradation).

3. There is a negative relationship between moral competence and social conservatism.

4. There is a positive relationship between conventional moral orientation (Stages 3 and 4) and social conservatism.

The hypotheses were tested in two studies. The second study was designed to replicate the results of the first study, as well as to refine the measurement of political orientation.

\section{Study 1}

\subsection{Method}

\subsubsection{Participants}

The sample consisted of 348 residents of Latvia, aged 18 to 67 (M=31.24, SD=9.92); $68.1 \%$ were female and $31.9 \%$ were male. Majority $(80.5 \%)$ of respondents were from cities, the rest were from small towns and rural areas. Almost two thirds $(63.8 \%)$ of the respondents had a higher education.

\subsubsection{Measurements}

Moral competence was measured using Lind's Moral Competence Test, or MCT (Lind, 1978, 2008), formerly known as Moral Judgment Test. Lind's Moral Competence Test is designed as a multivariate experiment (6 moral development stages $\times 2$ dilemmas $\times 2$ types of pro and con arguments) of one participant $(\mathrm{N}=1)$. The test consists of two dilemmas - the Workers' Dilemma and the Doctor's Dilemma - in which the action of the characters must be evaluated according to a Likert scale from -3 to +3 depending on to what extent an individual supports or does not support the respective action. Each dilemma has six pro arguments and six con arguments in relation to the action of the story's protagonist that must also be evaluated according to a Likert scale from -4 to +4 depending on to what extent they are acceptable to the respondent. Pro and con arguments of each dilemma correspond to the six Kohlbergian stages of moral development. The Moral Competence Test measures an individual's ability to judge controversial arguments in a discussion about a moral problem on the basis of moral principles and orientations rather than on the basis of personal opinion on the particular moral issue, or the corresponding social norms.

According to Lind's dual-aspect theory of moral behaviour (Lind, 1999, 2008), the Moral Competence Test has two indices: the cognitive index and the affective index:

- the moral competence index corresponds to the cognitive aspect of morality and reflects a respondent's ability to judge moral arguments according to their moral quality rather than according to the respondent's agreement or disagreement with an argument. The moral competence index is computed from the structure of responses by a multivariate analysis of variance (see Lind, 1999, 2008,). The moral reasoning index can range from 0 to 100, with higher numbers representing higher moral competence;

- the affective aspect of morality - moral orientation according to Kohlberg's six stages- is expressed by stage indices that show to what degree an individual prefers or rejects arguments of the corresponding stage. A separate index is calculated for each stage of moral development (ranging from -16 to +16 ), with higher numbers indicating a higher agreement with the arguments corresponding to the respective stage.

The importance of moral foundations was measured by the Moral Foundations Questionnaire MFQ-30 created by Graham, Haidt, and Nosek (Moral Foundations Questionnaire: 30-Item Full Version - MFQ-30, Graham, Haidt, \& Nosek, 2008). The questionnaire consists of two parts. In the first part (statements 1-16), a respondent must answer how relevant various statements related to five moral foundations are in deciding whether something is right or wrong. Sample items include whether or not someone suffered emotionally, whether or not someone showed a lack of respect for authority, whether or not someone was denied his or her rights, etc. A respondent is asked to 
indicate his/her opinion on a Likert scale ( 0 - not at all relevant, 5 - extremely relevant). In the second part (statements 17-32) a respondent must evaluate on a Likert scale (0 - strongly disagree, 5 - strongly agree) to what degree he/she agrees or disagrees with a number of statements expressing moral judgements (for example, compassion for those who are suffering as the most crucial virtue, calling certain acts wrong on the grounds that they are unnatural, etc.).

Cronbach's alphas were computed to check the internal consistency reliability of the MFQ 30 scales (for Care, Alpha = .57; Fairness, Alpha $=.52$; Loyalty, Alpha $=.64$; Authority, Alpha $=.65$; Sanctity, Alpha $=.78)$. The computed internal consistency indices can be evaluated as satisfactory, although they are lower than the ones obtained by the authors of the scale. An index for each moral foundations subscale was calculated by summing up the responses across the corresponding items.

In addition, previous research (Graham et al., 2011) has shown that the measurement of moral foundations can be reduced to two more inclusive indices: individualizing moral foundations (including care and fairness) and binding moral foundations (including loyalty, authority, and sanctity), and such a measurement has been successfully used in previous studies (e.g., Van Leeuwen \& Park, 2009). The Cronbach's Alpha for the individualizing moral foundations subscale was .70, and for the binding moral foundations subscale it was .84. Indexes for the two subscales were calculated by summing up the responses across the corresponding items.

Political orientation was measured on a 7-point Likert type scale (Jost, 2006) ranging from "extremely liberal" to "extremely conservative", with "moderate" as the midpoint.

\subsubsection{Procedure}

The data were collected from January 2009 until April 2009. One hundred and ninety-three respondents completed the questionnaire electronically on the Internet; 155 respondents completed the questionnaire in a paper-and-pencil version, administered by the first author of this paper.

\subsubsection{Results}

Spearman correlation coefficients among the variables were calculated to test the hypotheses (because several variables were not normally distributed). The results are depicted in the upper half of Table 1.

The first hypothesis was partially confirmed. Contrary to the predictions, there was a weak but significant negative correlation between moral competence and the importance of individualizing moral foundations $(r=-.11)$, and the fairness foundation in particular $r=-.12)$. At the same time, there was a significant negative correlation between the moral competence score and the importance of all binding moral foundations (loyalty/betrayal, authority/subversion, and sanctity).

The second hypothesis was partially confirmed. The results did not show any relationship between the importance of individualizing foundations and support for any of the stages of postconventional morality. A relationship was observed between support for Stage 3 arguments of the Kohlberg model, which correspond to moral orientation at the level of conventional morality, and the importance of binding moral foundations, although there was no relationship between support for Stage 4 arguments, which also correspond to conventional moral orientation, and the importance of binding moral foundations.

Table 1. Correlations (Spearman's rho) between MCT moral competence index, moral orientations, the importance of moral foundations, and conservative political orientation/ social conservatism.

\begin{tabular}{lcccccccc}
\hline Study 1 & \multicolumn{1}{c}{ Care Fairness Loyalty Authority Sanctity } & $\begin{array}{c}\text { Individualizing moral } \\
\text { foundations }\end{array}$ & $\begin{array}{c}\text { Binding } \\
\text { moral } \\
\text { foundations }\end{array}$ & $\begin{array}{c}\text { Political } \\
\text { orientation } \\
(1 \text { item })\end{array}$ & $\begin{array}{c}\text { Social } \\
\text { conservatism } \\
(8 \text { items })\end{array}$ \\
\hline $\begin{array}{l}\text { Moral } \\
\begin{array}{l}\text { competence } \\
\text { index }\end{array}\end{array}$ & .05 & $-.12^{*}$ & $-.25^{* * *}$ & $-.23^{* * *}$ & $-.25^{* * *}$ & $-.11^{*}$ & $-.29^{* * *}$ & $-.16^{* *}$ \\
Stage 1 & -.06 & -.05 & .07 & .01 & -.06 & .04 & -.01 & -.00 \\
\hline
\end{tabular}




\begin{tabular}{|c|c|c|c|c|c|c|c|c|}
\hline Stage 2 & -.03 & .05 & $.16^{\star \star}$ & .08 & -.02 & .03 & .07 & -.01 \\
\hline Stage 3 & .04 & .07 & $.24^{* *}$ & $.15^{\star *}$ & $.12^{*}$ & .08 & $.19^{* * *}$ & .10 \\
\hline Stage 4 & -.09 & .06 & .04 & .03 & -.07 & -.01 & -.01 & -.02 \\
\hline Stage 5 & .07 & .03 & .06 & .01 & -.04 & .06 & -.00 & -.07 \\
\hline Stage 6 & .09 & .10 & .09 & .06 & .05 & .10 & .08 & -.00 \\
\hline $\begin{array}{l}\text { Political } \\
\text { orientation }\end{array}$ & .03 & .06 & $13^{*}$ & $.26^{\star * *}$ & $.30^{* * *}$ & .05 & $.28^{* * *}$ & \\
\hline
\end{tabular}

\section{Study 2}

Moral

competence $\quad-.06 \quad-.11^{*}-1.19^{* * *}-.26^{* * *}-.21^{* * *} \quad-.09$

index

Stage 1

Stage 2

Stage 3

Stage 4

Stage 5

Stage 6

Political

orientation

Social

conservatism

$\begin{array}{ccccc}-.06 & -.11^{*} & -.19^{* * *} & -.26^{* * *} & -.21^{* * *} \\ & & & & \\ .00 & .14^{* *} & .16^{* *} & .17^{* *} & -.01 \\ .01 & .13^{*} & .12^{*} & .11^{*} & -.06 \\ .04 & .13^{*} & .25^{\star * *} & .29^{* * *} & .15^{\star *} \\ .03 & .13^{*} & .10 & .11^{*} & .03 \\ .06 & .07 & .00 & .01 & .04 \\ .19^{* * *} & .18^{* * *} & .11^{*} & .12^{*} & .09\end{array}$

-.09
.09
.08
.09
.09
.09
$.23^{\star * \star}$
01

$-.25^{\star * *}$

$-.16^{\star *}$

$-.23^{\star * *}$

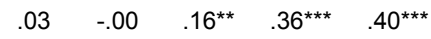

.01

$.23^{* \star *}$ $-.25^{\star \star \star}$
$.11^{\star}$
.05
$.26^{\star * *}$
.06
-.01
$.12^{*}$
$.37^{\star * *}$
$.65^{\star * *}$

$05-.10$

-.10
.00

$-.15^{\star *}$

$-.15^{* *}$

$-.08$

$-.11^{*}$

$-.13^{*}$

.07

$-.16^{\star *}$

$-.16^{\star *}$

$-.03$

$.46^{\star * *}$
$.11^{*}-.06$

${ }^{* * *} p<.001,{ }^{* *} p<.01,{ }^{*} p<.05$

\section{Study 2}

\subsection{Method}

\subsubsection{Participants}

The sample consisted of 361 residents of Latvia, aged 16 to $74(\mathrm{M}=33.76, S D=11.25)$. Of the respondents, $72.9 \%$ were female and $27.1 \%$ were male. Seventy three percent of the respondents were from cities, and the rest were from small towns and rural areas. Majority $(68.4 \%)$ of the respondents had a higher education.

\subsubsection{Measurements}

Measures of moral competence, moral orientations, and the importance of moral foundations were identical to those used in Study 1, with similar internal consistency indicators for the MFQ 30 subscales (Care, Alpha $=.61$; Fairness, Alpha $=.50$; Loyalty, Alpha $=.54$; Authority, Alpha $=.65$; Purity, Alpha $=.73$; individualizing moral foundations, Alpha $=.71$; binding moral foundations Alpha $=.84$ ).

To improve the validity of measuring the participants' political orientation, a Social Conservatism Scale was constructed. After the respondents had evaluated their political orientation on a seven-point scale (1 - very liberal, 4 - moderate centrist, 7 - extremely conservative), they were asked to express their opinion about a number of social phenomena, which, in accordance with previous research, are likely to polarize the opinions of conservatives and liberals (Altemeyer, 1996; Jost, Glaser, Sulloway, and Kruglanski, 2003; Jost, Nosek, \& Gosling, 2008; McCann, 2008; McCrae, 1996; Stenner, 2005), by indicating their response on a 7-point Likert scale where 1 strongly disagree, 7 - strongly agree. Eight items forming a coherent factor structure and high internal reliability (Alpha $=.90$ ) were used to measure social conservatism: abortion $(r)$, homosexual marriage $(r)$, prostitution $(r)$, greater influence of religion upon education, living in an unregistered marriage $(r)$, pornography $(r)$, change of traditional gender roles $(r)$, and the definition and protection of marriage in the Latvian constitution. The sum of the eight items, upon reversing the values of the reverse-scored items, forms the social conservatism index. High scores on the index indicate a tendency towards social conservatism while low scores tend to indicate social liberalism. 


\subsubsection{Procedure}

The data were collected in May-June 2010. Two hundred and sixty-nine respondents completed the questionnaire electronically on the Internet, and 92 respondents completed the questionnaire in a paper-and-pencil version.

\subsubsection{Results}

Spearman correlation coefficients among the variables were calculated to test the hypotheses (because several variables were not normally distributed). The results are depicted in the lower half of Table 1.

The first hypothesis again was partially confirmed. There was no significant correlation between the moral competence score and the importance of individualizing moral foundations, but similarly to Study 1 , there was a weak but significant negative correlation between moral competence and importance of fairness. At the same time, there was a significant negative correlation between the moral competence score and the importance of all binding moral foundations.

The 2nd hypothesis was partially confirmed - there was a relationship between support for Stage 6 arguments of the Kohlberg model, which correspond to post-conventional moral orientation, and individualizing moral foundations. However, there was no relationship between support for Stage 5 arguments, which also correspond to the post-conventional level, and the importance of individualizing moral foundations. A relationship was observed between support for Stage 3 arguments of the Kohlberg model, which correspond to conventional morality, and the importance of binding moral foundations. There was no significant relationship between support for Stage 4 arguments, which also correspond to conventional moral orientation, and the importance of binding moral foundations, except for a weak but significant correlation $(r=.11)$ between support for Stage 4 arguments, and the importance of moral foundation of authority. The positive correlations between support for Stage 6 arguments and the importance of binding moral foundations, and the foundations of loyalty/betrayal and authority/subversion in particular, were not predicted from theory.

\section{Discussion}

Previous research had established that moral competence is negatively related to social conservatism (Emler, 2002), and binding moral foundations are positively related to social conservatism (Graham et al, 2011), but the direct relationship between the intuitive and cognitive aspects of moral judgment had not been tested. Both studies reported here showed a robust negative relation between moral competence on the one hand, and the binding moral foundations of loyalty, authority, and sanctity, on the other.

An interesting and somewhat unexpected result was that there was no positive correlation between the individualizing moral foundations of fairness and care, and moral competence. Moreover, both studies revealed a weak but significant negative correlation between moral competence and the moral foundation of fairness. This finding suggests that the importance of individualizing moral foundations is clearly distinct from the ability to use care- and fairness-related arguments in moral reasoning.

According to Lind (Lind, 2003a), a large number of moral values and principles require a highly developed moral competence in order for an individual to be able to solve moral dilemmas and make balanced decisions. Consequently, the importance of the binding moral foundations impedes moral reasoning and makes the formation of moral judgment more difficult. An individual facing a morally sensitive situation (or moral dilemma) may come up with several, often competing, moral intuitions (Haidt, 2001); such an internal conflict can be resolved by finding a meta-principle that is able to induce a new intuition and a new attitude toward the existing situation. Individuals for whom individualizing moral foundations are important, but binding moral foundations are less important, find it easier to cognize a meta-principle that can resolve such a moral conflict, while 
preserving consistency in reasoning in the evaluation of moral arguments. This is of special importance in Lind's Moral Competence Test. Such a situation can be conceptualized as a multiattribute choice where the number of criteria for evaluation of alternatives complicates the choice of optimal alternative (Shafir \& LeBoeuf, 2004).

Coordinated and consistent evaluation of test arguments according to their moral quality is the basis of a high moral competence index. Respondents who consider the importance of both individualizing moral foundations - care/harm and fairness/cheating - as well as binding moral foundations - in-group loyalty, respect for authority, and concern with sanctity - were faced with a more complex analytical problem and produced lower moral competence scores in the Moral Competence Test. Moreover, insufficient cognitive resources or constraining circumstances (e.g. not enough time to study issues in-depth) often influence the resolution of complicated cognitive issues. The fact that conservative respondents received lower moral competence scores indicates that they evaluated the arguments in the Moral Competence Test inconsistently and mostly in compliance with personal or ideological opinions, not according to the moral quality of the arguments. It is possible that the conservative respondents did not try to analyze the moral quality of the pro and con arguments included in the Moral Competence Test, but relied instead on an evaluation of the respective problems as prescribed by ideological prescriptions that are more easily accessible in the memory.

One of the tasks of further research is related to the improvement of instruments of psychological research on morality. Almost all psychological tests investigating morality, including Lind's Moral Competence Test (MCT), have been created in Western individualist countries - in particular, USA and Germany - in the 1950s-1980s, during which the importance of cognitive factors in moral development and the solution of moral problems were emphasized. Moreover, the content of these tests reflects primarily the principles of individualizing moral foundations and autonomy ethics. When these moral reasoning tests are used in collectivist countries or in social groups with conservative political views or groups of highly religious respondents, moral competence scores are substantially lower than in Western individualist countries or in more liberal groups. In search for unbiased instruments for measurements of moral judgment, it would be advisable to create methods that are based not solely on individualist morality values, but address issues of social and religious ethics, that would be suitable for use in different cultures and political and religious groups.

The overall correlation pattern between the scores of moral orientation and moral competence on the one hand, and importance of moral foundations and political orientation on the other hand was relatively weak and only partially consistent with the theoretical predictions. The results suggest that constructs used in the rational-cognitive and social-intuitionist perspectives on moral judgment are conceptually different. The rational-cognitive approach is based on a narrower definition of morality and its operationalization of cognitive reasoning is more ability- or competence-based. In contrast, the social-intuitive approach uses a much more inclusive definition of moral domain, and its measures of moral reasoning (the importance of moral foundations) is more akin to measurement of values or attitudes. Integrating the two approaches appears to be a challenging task, as it may require mutually changing both the theoretical assumptions of what should or shouldn't be considered "moral" in human judgment and reasoning, and changing the way moral judgment and reasoning are measured psychometrically.

\section{References}

Altemeyer, R. A. (1996). The authoritarian specter. Cambridge, MA: Harvard University Press.

Crowson, H. M., \& DeBacker, T. K. (2008). Political identification and the Defining Issues Test: Reevaluating an old hypothesis. Journal of Social Psychology, 148 (1), 43-60.

Duckitt, J., \& Sibley, C. G. (2009). A dual-process motivational model of ideology, politics, and prejudice. Psychological Inquiry, 20 (2/3), 98-109.

Emler, N. (2002). Morality and political orientations: An analysis of their relationship. European Review of Social Psychology, 13, 259-291.

Emler, N., Renwick, S., \& Malone, B. (1983). The relationship between moral reasoning and political orientation. Journal of Personality and Social Psychology, 45 (5), 1073 - 1080. 
Federico, C. M., Weber, C. R., Ergun, D., \& Hunt, C. (2013). Mapping the connections between politics and morality: The multiple sociopolitical orientations Involved in moral intuition. Political Psychology, 34 (4), 589-610.

Feldman, S., \& Johnston, C. (2014). Understanding the determinants of political ideology: Implications of structural complexity. Political Psychology, 35, 337-358.

Graham, J., Haidt, J. \& Nosek, B. (2008). Moral Foundations Questionnaire, MFQ 30 revised in July 2008. Extracted 8.12.2008. from http://faculty.virginia.edu/haidtlab/mft/index.php?t=questionnaires

Graham, J., Haidt, J., \& Nosek, B. A. (2009). Liberals and conservatives rely on different sets of moral foundations. Journal of Personality and Social Psychology, 96, 1029-1046.

Graham, J., Haidt, J., Nosek, B. A., Iyer, R., Koleva, S., \& Ditto, P. H. (2011). Mapping the moral domain. Journal of Personality and Social Psychology, 101, 366-385.

Haidt, J. \& Joseph, C. (2004). Intuitive ethics: How innately repaired intuitions generate culturally variable virtues. Daedalus, Fall, 55-66.

Haidt, J. (2001). The emotional dog and its rational tail: A social intuitionist approach to moral judgment. Psychological Review 108, 814-834.

Haidt, J. (2007). The new synthesis in moral psychology. Science, 316, 998 - 1002.

Haidt, J. (2010). Moral psychology must not be based on faith and hope: Commentary on Narvaez (2010). Perspectives on Psychological Science, 5, 182-184.

Haidt, J., \& Graham, J. (2007). When morality opposes justice: Conservatives have moral intuitions that liberals may not recognize. Social Justice Research, 20 (1), 98-116.

Jost, J. T. (2006). The end of the end of ideology. American Psychologist, 61, 651-670.

Jost, J. T., Federico, C. M., \& Napier, J. L. (2009). Political ideology: Its structure, functions, and elective affinities. Annual Review of Psychology, 60, 307-337.

Jost, J. T., Glaser, J., Kruglanski, A. W., \& Sulloway, F. (2003). Political conservatism as motivated social cognition. Psychological Bulletin, 129, 339-375.

Kohlberg, L. (1968). Moral Development. In International Encyclopedia of the Social Sciences (pp. 483 - 494$).$ NewYork: Crowell, Collier \& Macmillan.

Kohlberg, L. (1976). Moral stages and moralization: The cognitive- developmental approach. T. Lickona (Ed.), Moral development and behavior: Theory, research and social issues (pp. 31-53). New York: Holt, Rinehart \& Winston.

Kohlberg, L. (1977). Assessing moral stages: A manual, Part I, Introduction. Cambridge MA: Center for Moral Education, Harvard University.

Kugler, M., Jost, J., \& Noorbaloochi, S. (2014). Another look at Moral Foundations Theory: Do authoritarianism and social dominance orientation explain liberal-conservative differences in 'moral' intuitions? Social Justice Research, 27(4), 413-431.

Lind, G. (1978). Der 'Moralisches-Urteil-Test' (m-u-t). Anleitung zur Anwendung und Weiterentwicklung des Tests. [The moral judgment test MJT: guide to the application and further development of the test]. In L.H. Eckensberger, Ed., Entwicklung des moralischen Urteils - Theorie, Methoden, Praxis. [Development of moral judgment - theory, methods, practice]. Saarbrücken. University print, pp. 337-358.

Lind, G. (1986). Cultural differences in moral judgment competence? A study of West and East European university students. Behavior Science Research, 20, 208-225.

Lind, G. (1999). Scoring of the Moral Judment Test (MJT). Extracted 1.10.2007 from http://www.unikonstanz.de/ag-moral/pdf/Lind-1999 MJT-Scoring-E.pdf

Lind, G. (2002). Ist Moral lehrbar? Ergebn̄isse der modernen moralpsyhologischen Forscung [Can morality be taught? Research findings from modern moral psychology]. Berlin: Logos Verlag.

Lind, G. (2003a). Moral ist lehrbar. Handbuch zur Theorie und Praxis der moralischen und demokratischen Bildung [Morality can be taught. Handbook on theory and practice of moral and democratic education]. München: Oldenbuorg Schulbuchverlag $\mathrm{GmbH}$.

Lind, G. (2003b). The cross-cultural validity of the Moral Judgment Test: Findings from 27 cross-cultural studies. Paper prepared for the American Psychological Association APA, Aug. 18-22, 2005. Extract 20.10. 2009 from http://www.uni-konstanz.de/ag-moral/b-liste.htm\#lind_2005_30years

Lind, G. (2006). Effective moral education: The Konstanz method of dilemma discussion. Hellenic Journal of Psychology, 3, 189-196.

Lind, G. (2008). The meaning and measurement of moral judgment competence revisited - A dual-aspect model. In: D. Fasko, W. Willis, Eds., Contemporary Philosophical and Psychological Perspectives on Moral Development and Education. Cresskill. NJ: Hampton Press, S. $85-220$.

McCann, S. J.H. (2008). Societal threat, authoritarianism, conservatism, and U.S. state death penalty sentencing (1977-2004). Journal of Personality and Social Psychology, 94 (5), 913-923.

McCrae, R. R. (1996). Social consequences of experiential openness. Psychological Bulletin, 120, $323-337$.

Narvaez, D. (2010). Moral complexity: The fatal attraction of truthiness and the importance of mature moral functioning. Perspectives on Psychological Science, 5, 163-181. 
Nilsson, A., \& Erlandsson, A. (2015). The Moral Foundations taxonomy: Structural validity and relation to political ideology in Sweden. Personality \& Individual Differences, 76, 28-32.

Piaget, J. (1932/1965). The moral judgment of the child. New York: Free Press.

Raaijmakers, Q. A. W., \& Van Hoof, A. (2006). Does moral reasoning represent sociomoral structure or political ideology? A further exploration of the relations between moral reasoning, political attitudes, consistency of moral thought, and the evaluation of human rights in Dutch young adults. Social Behavior and Personality, $34,617-638$

Shafir \& LeBoeuf (2004). Context and Conflict in Multiattribute Choice. In Eds. D.J. Koehler, N. Harvey Blackwell Handbook of Judgment and Decision Making (pp. 342 - 357), Blackwell Publishing Ltd.

Snarey, J. R. (1985). Cross-cultural universality of social-moral development: A critical review of Kohlbergian research. Psychological Bulletin, 97, 202-232.

Stenner, K. (2005). The authoritarian dynamic. New York: Cambridge University Press.

Turiel, E. (1983). The Development of social knowledge. Cambridge: Cambridge University Press.

Turiel, E., Hildebrandt, C., \& Wainryb, C. (1991). Judging social issues: Difficulties, inconsistencies, and consistencies. Monographs of the Society for Research in Child Development, 56, 1-103.

Van Leeuwen, F., \& Park, J. H. (2009). Perceptions of social dangers, moral foundations, and political orientation. Personality and Individual Differences, 47, 169-173.

Weber, C. R., \& Federico, C. M. (2013). Moral foundations and heterogeneity in ideological preferences. Political Psychology, 34(1), 107-126.

\section{Appendix}

\section{Summary of Kohlberg's stages of moral development (adapted from Kohlberg, 1976)}

\begin{tabular}{|c|c|c|c|}
\hline $\begin{array}{l}\text { Level/stage } \\
\text { Level I: Pre-Convent }\end{array}$ & $\begin{array}{l}\text { Criteria for morally right behavior } \\
\text { tional }\end{array}$ & Individual motivation & Social perspective \\
\hline $\begin{array}{l}\text { Stage 1. Obedience } \\
\text { and punishment }\end{array}$ & $\begin{array}{l}\text { - Observe rules when transgressing } \\
\text { is punished } \\
\text { - Defer to authority } \\
\text { - Focus on the immediate } \\
\text { consequences of behavior }\end{array}$ & $\begin{array}{l}\text { - Avoidance of punishment/ } \\
\text { negative consequences of } \\
\text { behavior }\end{array}$ & $\begin{array}{l}\text { - Egocentric perspective } \\
\text { - No recognition of others' point of } \\
\text { view } \\
\text { - Reasoning based on external } \\
\text { observations, ignoring internal } \\
\text { intentions }\end{array}$ \\
\hline $\begin{array}{l}\text { Stage } 2 . \\
\text { Instrumental } \\
\text { exchange }\end{array}$ & $\begin{array}{l}\text { - Observe rules when it serves } \\
\text { personal interests and needs } \\
\text { - Follow reciprocity in social } \\
\text { interaction }\end{array}$ & $\begin{array}{l}\text { - Serving personal interests } \\
\text { and needs }\end{array}$ & $\begin{array}{l}\text { - Individualist perspective } \\
\text { - Acknowledgment of others' } \\
\text { interests as long as it is instrumental } \\
\text { for the self }\end{array}$ \\
\hline \multicolumn{4}{|l|}{ Level II: Conventional } \\
\hline $\begin{array}{l}\text { Stage } 3 . \\
\text { Interpersonal } \\
\text { conformity }\end{array}$ & $\begin{array}{l}\text { - Conform to the expectations of } \\
\text { others } \\
\text { - Conform to stereotypes of one's } \\
\text { social roles } \\
\text { - Develop relationships with close } \\
\text { others, based on trust, respect, } \\
\text { gratitude, loyalty }\end{array}$ & - Gaining approval of others & $\begin{array}{l}\text { - Relational perspective } \\
\text { - Recognition of interests and needs } \\
\text { of others } \\
\text { - Integration of different views and } \\
\text { opinions }\end{array}$ \\
\hline $\begin{array}{l}\text { Stage } 4 \text {. Societal } \\
\text { conformity }\end{array}$ & $\begin{array}{l}\text { - Observe laws and follow one's } \\
\text { social duties } \\
\text { - Serve the society }\end{array}$ & - Maintaining the social order & $\begin{array}{l}\text { - Social systems perspective } \\
\text { - Differentiation between social } \\
\text { convention and interpersonal } \\
\text { consent } \\
\text { - Responsibility for the welfare of } \\
\text { others within society }\end{array}$ \\
\hline \multicolumn{4}{|c|}{ Level III: Post-Conventional (Principled) } \\
\hline $\begin{array}{l}\text { Stage } 5 \text {. Social } \\
\text { contract }\end{array}$ & $\begin{array}{l}\text { - Respect different values and } \\
\text { opinions } \\
\text { - Follow social contract to ensure } \\
\text { the greatest good for the greatest } \\
\text { number of people }\end{array}$ & $\begin{array}{l}\text { - Observing and maintaining } \\
\text { social contract }\end{array}$ & $\begin{array}{l}\text { - Contractual perspective } \\
\text { - Recognition of (and respect for) a } \\
\text { plurality of values and opinions } \\
\text { - Compromise-seeking }\end{array}$ \\
\hline $\begin{array}{l}\text { Stage } 6 \text {. Universal } \\
\text { ethical principles }\end{array}$ & $\begin{array}{l}\text { - Use universal ethical principles } \\
\text { adapted to the particular case }\end{array}$ & $\begin{array}{l}\text { - Acting in line with personal } \\
\text { beliefs in universal ethical } \\
\text { principles }\end{array}$ & $\begin{array}{l}\text { - Universalist perspective } \\
\text { - Belief in equality and worth of all } \\
\text { human beings }\end{array}$ \\
\hline
\end{tabular}

